32

\title{
Collective Intentionality in Non-Human Animals
}

\author{
Robert A. Wilson
}

\section{INTRODUCTION}

'Collective intentionality', write Schweikard and Schmid in their recent Stanford Encyclopedia of Philosophy review of the topic, "is the power of minds to be jointly directed at objects, matters of fact, states of affairs, goals, or values" (Schweikard and Schmid 2013). As Schweikard and Schmid's broader overview indicates, and as reflected in the current volume, collective intentionality has been primarily deployed in recent discussions of human cognition and sociality. In particular, over the past 20 years, collective intentionality has been used to explore putatively distinct forms of human cooperation and conflict, the role of institutions in human social life, and even the broader nature of social reality itself (Gilbert 1996; Searle 1995; Tomasello 1999; Tuomela 2007).

Whatever else it may be, collective intentionality has come to be conceived as some kind of crowning achievement of our species, and perhaps of our closest ancestors and living relatives, a sort of keystone accomplishment that brings in its wake new forms of sociality. Collective intentionality builds on and utilizes forms of individual cognition that are themselves distinctively human, whether they be metacognitive, modular, or general purpose. In that context, questions about how collective intentionality both develops ontogenetically and evolved phylogenetically are important, albeit secondary. They are questions about how individuals move, or the species moved, from a state without collective intentionality to a state with collective intentionality. Two recent publications on collective intentionality from influential researchers exemplify this perspective on collective intentionality.

In his Making the Social World: The Structure of Human Civilization (2010), John Searle emphasizes the importance that collective intentionality plays in human sociality through its role in creating institutional reality, elaborating on a view Searle first articulated at length in his Constructing the Social World, where he had noted that he used "social facts" and "collective intentional facts" so as to be coextensive (Searle 1995: 122). 
For Searle, the collective acceptance or recognition of what he calls "status functions" assigned to brute physical facts is what creates institutional reality, and it is institutional reality that marks off distinctive forms of human sociality. Such collective mental phenomena 'of the sort we get in organized societies are themselves dependent on and derived from the mental phenomena of individuals' (Searle 2010: 4) and, for Searle, all 'intentionality, whether collective or individual, has to exist inside individuals' heads' (2010: 44). So according to Searle, distinctive human sociality is institutionally mediated, where institutional reality is brought into existence through forms of collective intentionality, which itself derives from in-the-head individual intentionality.

Michael Tomasello's A Natural History of Human Thinking (2014) concurs with Searle's view of the significance of collective intentionality for human sociality, and defends a particular, two-step evolutionary trajectory for the rise of collective intentionality that links it tightly to the origins of human culture. Although individual intentionality is possessed by humans and our closest living relatives in the primate order, Tomasello takes what he calls joint attention to be distinctively human, resting on forms of sharing or small-scale collaborative behavior between restricted numbers of individuals. Joint attention, in turn, becomes extended as 'group life as a whole became one big collaborative activity, creating a much larger and more permanent shared world, that is to say, a culture' (Tomasello 2014: 5). This new collaboration, together with the conventional, institutional, and normative forms of communication it involves, are what Tomasello calls collective intentionality, a kind of group-mindedness (2014: 5-6) that only human beings and their recent ancestors possess.

The anthropocentric perspective reflected in such views of collective intentionality are manifest more generally in the recent literature. For example, neither Schweikard and Schmid's (2013) article on collective intentionality, nor Chant, Hindriks and Preyer's introduction to their collection From Individual to Collective Intentionality (2014) even so much as mention non-human animal cognition. From such perspectives, an article on collective intentionality in non-human animals could be very brief, except insofar as it might help to delineate what collective intentionality is not. In short: there isn't any collective intentionality in the non-human animal world to be found.

We could, of course, break the visual silence here, avoiding the professional embarrassment that one should feel in writing on a non-topic, by discussing all the phenomena that one might think involve collective intentionality in non-human animals but don't really, or forms of proto-collective intentionality, or perhaps collective proto-intentionality, that one can find in non-human animals. Even so, I think it would be hard to completely suppress the thought that one was whistling in the dark, and that summers really are for something else.

Perhaps, at the end of the day, that's what readers will think this paper does. Fortunately for me at least (even if not for my summer), I think there is much more to be said in a positive and constructive vein about collective intentionality itself in non-human animals. Doing so involves probing at the concept of collective intentionality fairly directly (Section 2), considering the various forms that collective intentionality might take (Section 3), showing some sensitivity to the history of appeals to that concept and its close relatives (Section 4), and raising some broader questions about the relationships between sociality, cognition, and institutions by discussing two different possible cases of collective intentionality in non-human animals: that of the social insects (Section 5) and 
that of highly social mammals, such as canines (Section 6). If the discussion here is on track, then the widely shared perspective on collective intentionality exemplified by the work of Searle and Tomasello needs to be reconsidered.

\section{COLLECTIVE INTENTIONALITY: THE WHAT AND THE WHERE}

Although "intentionality" is a philosophical term of art, something that is often forgotten, the phenomena that it refers to are commonplace, particularly in how we think about the mental activities of individuals. Much of that activity is directed at, about, or represents how things are, were, or might be, in the world. Our mental lives are suffuse with activities-believing, desiring, imagining, remembering, pretending, fearing-that are representational or intentional in this way. Thus, intentionality is integral to the folk conception of individual minds. Indeed, intentionality was taken by Franz Brentano (1874) to be sufficiently central to having a mind that he famously characterized it as 'the mark of the mental'.

The primary ground for thinking that individuals have mental states with intentionality is epistemic and explanatory: such states are required for us to systematically grasp why human agents do what they do. Challenges issued to the claim that individuals have mental states with intentionality, such as behaviorism and eliminative materialism, lost out as viable alternatives in the philosophy of mind and cognitive science, which long ago made peace with an appeal to the intentionality of mental states as an integral part of the explanatory toolkit needed to understand human behavior and action (R.A. Wilson 1999).

Discussions of collective intentionality arose more recently from the same kind of epistemic ground within the theory of action (Searle 1990), but from the outset faced the same challenge that individual intentionality has bettered over time. This continuing challenge to the idea of collective intentionality is reflected in the more tentative way in which collective intentionality is often introduced into discussions of collective human action: might we need to posit intentionality that goes beyond the familiar forms of individual intentionality in order to explain at least some human social behaviors and actions?

More particularly, much human social behavior is cooperative, shared, or joint. We do things together: we work and play, we walk and talk, we celebrate and mourn, we laugh and cry. There seems little reluctance to view ourselves as undertaking such behaviors or actions together, to accept collective action, in addition to individual action. Even though collective action requires (and has received) further philosophical analysis, those who want to deny that there is such a thing as collective action face an uphill battle. Collective actions, such as building a fire together or holding hands, are no more ontologically dubious than the corresponding individual actions.

Not so with the underlying states that explain such collective behavior or action itself. Collective psychology, group minds, shared and joint cognition of various kindsintentions, commitments, beliefs - all seem to invoke a mental ontology that goes beyond that of our common-sense thinking about minds and intentionality, and beyond the comfort zone that individual intentionality has found for itself in contemporary philosophical thinking about the mind.

For this reason, a major issue permeating the collective intentionality literature is whether one can provide an adequate account of the phenomena to be explained while

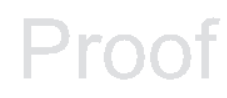


restricting oneself to what Schweikhard and Schmid (2013) call the individual ownership claim: 'collective intentionality is had by the participating individuals, and all the intentionality an individual has is his or her own'. If the individual ownership claim is true, then we seem at least primed to reduce collective intentionality to individual intentionality, plus some other non-intentional remainder. And if distinctively human cooperative, shared, or joint behavior and action is made possible by collective intentionality, so conceived, then we have a reductionist framework for understanding those aspects of human social life.

I want to suggest several ways in which one might adjust this overall perspective on collective intentionality that makes space for collective intentionality in the non-human animal world, but which also appeals to a form of the individual ownership claim. This is a particular form of what I have, elsewhere (R.A. Wilson 2001, 2004), called the social manifestation thesis. I begin with two reminders, the first about two forms of collective action, the second about the variety there is to collective intentionality itself.

\section{FROM COLLECTIVE INTENTIONALITY TO COLLECTIVELY ACTING}

The phrase "collective intentionality" itself can take on a reifying tendency: to think of intentionality as a thing of some kind that collectives or groups have or possess. Since collective action-or, better, collectively acting -is taken to be a relatively unproblematic phenomenon, an explanandum in search of an explanans, I want to suggest that we begin by reminding ourselves of two forms that collectively acting might take, neither of which are simply summative of the actions of individuals in the corresponding group. We might call these the distributive and the joint or shared forms of collectively acting.

A collective or group of individuals acts distributively when the components of the overall action are distributed across the actions of those individuals. A crowd's gathering at one time, and later dispersing, are two distributed forms of collectively acting, something that a group does through the actions of individuals. But distributive group action can also involve specialized individual actions, such as when a group builds a shelter or catches some food, where each individual does something distinctive that contributes to the overall group accomplishment.

In distributive collective action, the group does something that no individual in the group herself does, except insofar as she contributes to the collective action itself. To take a simplified example, one beaver finds and transports waterlogged debris to a particular site in a creek; a second beaver then places that material in the growing dam. The collective action of building a shelter-a beaver lodge or dam-is distributed across this pair of actions. To find and transport that material, or to arrange it, is to build a shelter only insofar as these component actions form part of the collective action.

For there to be joint or shared collective action, there needs to be not simply distributive collective action but in addition some kind of coordinating glue that makes it an action that is completed together intentionally. When a team of contractors builds my house, or a restaurant cooks me a meal, there is not simply distributed collective action but the kind of coordination and cooperation that makes for joint or shared collective action. One hypothesis is that joint or shared intentionality, particularly shared intentions, is what provides this coordinating glue. Such shared intentions have been central to

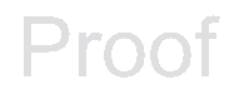


the literature on collective intentionality, where they are often called "we-intentions": first-person plural intentions.

Finally, I turn to the second of my promised reminders. Although collective intentions feature prominently in the literature on collective intentionality, intentions are just one of many mental states that might be possessed by individuals or by collectives. An intention is a particular kind of propositional attitude or mental act, one related in specific ways to consciousness, planning, and behavior. But groups, like individuals, may also choose, plan, try, remember, perceive, sense, believe, desire, enjoy, or regret. At least in principle, each of those mental activities can exemplify collective intentionality. Indeed, it has been these forms of putative group-level intentionality that were postulated in both the biological and social sciences in the more distant past of our attempts to understand collective action via the idea of a group mind.

\section{GROUP MINDS AND THE SOCIAL MANIFESTATION THESIS}

As the evolutionary biologist David Sloan Wilson (1997a, 1997b) pointed out nearly 20 years ago in the context of his successful revival of group selection as a viable mechanism for evolutionary change, the idea that groups of individual organisms, including human agents, have minds of some kind was once widely accepted in the social sciences. Wilson pointed to a number of the founders of sociology and anthropology, such as Emile Durkheim and William McDougall, as proponents of the idea that human groups, as well as human individuals, could literally have minds of some kind. To capture a broad set of views that one might argue are found in the works of such figures, I characterized the corresponding view as follows:

Group mind hypothesis: groups of individual organisms can have or can be thought of as having minds in something like the way in which individual organisms themselves can have minds.

(R.A. Wilson 2004: 267; cf. R.A. Wilson 2001: S263)

Wilson argued that group-level adaptations included not only physical activities but cognition, since 'groups can also evolve into adaptive units with respect to cognitive activities such as decision making, memory, and learning' (D.S. Wilson 1997a, S128). Here Wilson took himself to be advocating a form of the group mind hypothesis with respect to both human and non-human animals.

In exploring both the kind of claim that Wilson makes about the history of the social sciences and the contemporary revival of that tradition that he was himself advocating, I argued that such revivalist enthusiasm is somewhat misplaced (R.A. Wilson 2001, 2004: Ch.11-12). This is because much of the relevant literature here is more plausibly viewed as advocating not the group mind hypothesis but what I called the social manifestation thesis:

social manifestation thesis: individuals have properties, including psychological properties, that are manifest only when those individuals form part of a group of a certain type.

(R.A. Wilson 2004: 281; cf. R.A. Wilson 2001: S265) 
According to the social manifestation thesis, it is individuals rather than groups that have psychological properties and thus minds, but the social groups to which those individuals belong play some kind of important role in the possession of those properties. That role was not simply as a background condition or as a causal trigger for cognition, but partially constitutive or realizing of the manifestation of cognition itself. Having offered, in the previous chapters in the book, a sustained-some might say prolonged-articulation and defense of the idea that individual cognition was extended (R.A. Wilson 1994; Clark and Chalmers 1998; Clark 2008), I intended the social manifestation thesis to be read as a particular form of the hypothesis of extended cognition:

hypothesis of extended cognition: individual cognition sometimes (regularly, often, always?) involves the operation of systems that physically extend beyond the body of the individual cognizer.

(see also Adams and Aizawa 2008; Rupert 2009; Wilson and Clark 2009; R.A. Wilson 2014)

Offering a more deflationary alternative to the group mind hypothesis, this version of the social manifestation thesis has been explored in the contexts of human remembering (Barnier et al. 2008), moral psychology (Sneddon 2011), and more general discussions of human collective intentionality (Huebner 2013; Rupert 2014; Theiner 2014).

The basic idea in positing the social manifestation thesis, especially when married with the hypothesis of extended cognition, was to pose a challenge to those who viewed an ontology populated by group minds and collective intentionality as having the kind of explanationist justification already mentioned. By accepting an enriched view of individual cognition-seeing it as embodied, embedded, extended, and enactive, and recognizing the social dimensions to this " $4 \mathrm{E}$ " view of human cognition - and showing that such a view could account for at least paradigm cases of putative collective intentionality, the challenge to the proponent of group minds was to identify phenomena that require, in addition or instead, human group-level cognition. That challenge has been taken up, both directly and indirectly, in recent defenses of the group mind hypothesis (e.g. Theiner 2014; Huebner 2013).

As should be clear, the social manifestation thesis itself does not entail the hypothesis of extended cognition. As such, that thesis admits of versions that are individualistic not only about the bearers of cognitive states but about the nature of those states themselves. That is, one could accept the social manifestation thesis and hold both that the bearers of intentional states are individuals and that those states supervene on the intrinsic, physical properties of their bearers. Such readings of that thesis are compatible with the dominant perspective on collective intentionality articulated by Schweikard and Schmid's individual ownership claim that we also find in Searle and Tomasello.

Drawing on an analogy to a riffing jazz musician, Tomasello captures the role of the social context in modern human cognition in saying that ' $\mathrm{h}$ ] uman thinking is individual improvisation enmeshed in a sociocultural matrix' (2014: 1). Starting from self-contained individual intentionality, Tomasello's shared and collective intentionality are elaborations on such head-bound cognition, elaborations that are shaped by and shape new emerging forms of human sociality marked by heightened cooperativeness. If Tomasello accepts the social manifestation thesis, it is likely to be an individualistic view of that thesis, in both senses. 
We have already seen that Searle thinks that intentionality, whether collective or individual, has to exist inside individuals' heads' (2010: 44). Searle's antipathy to the extended mind, reflecting his long-standing commitment to individualism about mental states, was apparent recently in his off-hand comment that it upsets me when I read the nonsense written by my contemporaries, the theory of extended mind makes me want to throw up' (Boag 2014). This report of Searle's (natural?) digestive state reflects his own strong and long-standing commitment to individualism about mental states, and thus any version of the social manifestation thesis that he accepts is also likely to be doubly individualistic. If Searle rejects the social manifestation thesis, it is likely because he finds the very idea of socially manifested intentional states to be too close to the other nonsense written by his contemporaries that he can't stomach.

The final point to make here is that since the $4 \mathrm{E}$ view of human cognition makes intentionality very much something that is neither contained within nor bounded by the head of the individual cognizer, it sits at best uneasily with the project of providing a reductive account of collective intentionality (cf. Rupert 2005). On this view, individual cognition itself is constitutively social, and so there is no reductive pathway leading, either ontogenetically or evolutionary, from pre-social individual intentionality to collective intentionality to sociality. Reflection on the sociality and cognition of non-human animals can make this claim both more concrete and readily defensible.

\section{NON-HUMAN ANIMALS, SOCIALITY, AND COGNITION: THE SOCIAL INSECTS}

In the mobile living world, sociality is pervasive, and it is easy to understand why. Living agents that move around need to have means of responding (relatively) rapidly to features of their local environments that can change (relatively) quickly because of the movement of the agent. This is why sensory systems are ubiquitous in the mobile living world (cf. MacIver 2009). When you are moving around, your proximal environment tends to change more rapidly in ways that are relevant to your survival and reproduction than it does when you have a sedentary way of life. This is why mice have elaborate, quick-time sensorimotor systems, but trees do not.

And any mobile living agent, unless it is extremely unfortunate or unusual, will often encounter other mobile living agents that are endowed with something like the same capacities and powers that it has, in part because it will be reproduced by, and often with, other such agents. For a mobile living agent to track, respond to and even anticipate the behavior of other mobile agents requires even more sensory or cognitive sophistication than simply to track, respond to and even anticipate other kinds of environmental resources.

Social interactions in the non-human animal world take many overlapping forms. They can be, among other things, reproductive, cooperative, competitive, predatorial, protective, domineering, resource-securing, mutualistic, exploitative, parasitic, pathogenic, altruistic, or sacrificial. Many of these forms of sociality take place with very little cognitive mediation, given that they occur between critters whose individual cognitive power is likely quite limited. Much of this sociality is merely aggregative in that it is the outcome simply of aggregated individual behaviors that require little coordination with

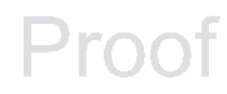


conspecifics. Jellyfish, like real fish, tend to form social aggregates; such jellyfish blooms, unlike the fish schools they may superficially resemble, fall into this category. But as perhaps suggested by the brief discussion of distributive collective action, some forms of sociality in non-human animals have generated versions of the group mind hypothesis, something missed by an exclusive focus on human agency and collective intentionality.

Alongside what I have called the collective psychology tradition that postulates group minds in human social groups, there is an independent superorganism tradition that posits group minds in special sorts of non-human animal social groups (R.A. Wilson 2004: 274-80). As the name suggests, these special groups are sometimes referred to as superorganisms, a term coined by the Harvard entomologist William Morton Wheeler in 1920 as part of a series of reflections on insect colonies (Wheeler 1911, 1920, 1923, 1926). Although the ascription of mental states to such colonies does not form a central part of the early part of the superorganism tradition, more recently entomologists have articulated and defended the group mind hypothesis, particularly with respect to honey bees (Seeley et al. (1991); Seeley (1995, 1997, 2003); Seeley and Visscher (2003); see also Huebner (2013: 230-33)).

Consider the Hymenoptera-the wasps, ants and bees-which, together with the termites, are commonly known as the "social insects." As their moniker suggests, the Hymenoptera exhibit much sociality-from nest-cleaning behavior to hive temperature regulation requiring the coordination of the behaviors of thousands of bees. Although individual wasps, ants, and bees clearly have some kind of intentionality, the clearest forms it takes are perceptual or sensory in nature, and only dubiously involve what we might call cognition central: belief, reason, and thought.

Despite this, social insect colonies as a whole or in sizeable part, accomplish impressive outcomes that are very naturally described by attributing perceptual or sensorimotor properties to those groups of organisms. These include the perceptual and communicative abilities involved in gathering information about food sources and the motoric capacities to utilize resources and avoid predators and dangers in the world. Some of these abilities, such as the ability of a bee colony to locate distance sources of nectar and regulate the relative number of foragers and hiver workers in accord with the richness of the source, or the ability of a termite colony to rapidly repair damage to its nest, manifest both some level of intentionality and a degree of concern over the integrity of the colony. Yet it is very implausible to think that these are possessed by individual members of the hive, nest, or colony. In short, the behavior of at least some groups is such that it seems directed at self-preservation, where the self here is a colony, and the means of achieving that goal involves group-level decision-making that draws on collectively distributed perception and sensing.

The relevant, putative mental activities here-for example, perceiving, remembering, deciding, monitoring - are group-only traits, traits possessed only by a group, and not by the individuals that comprise the group. For that reason, appealing to the social manifestation thesis as an explanatory alternative to the group mind hypothesis is much less plausible than it is in the case of human cognition, where the traits under consideration are multi-level traits, traits that either individuals or groups could, in principle possess.

How is this relevant to collective intentionality? If, following Schweikard and Schmid (2013), collective intentionality just is 'the power of minds to be jointly directed', there is no collective intentionality without individual minds. Georg Theiner has suggested more

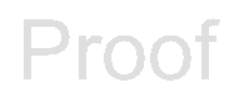


directly that what he calls "hive cognition" is not really an example of the group mind hypothesis, defined as the view that 'there are collective types of minds that comprise two or more singular minds among their constitutive parts' (2014: 301). Since there are no singular minds among the constitutive parts of a beehive, there is no more collective intentionality in these cases than there is collective intentionality in a single brain that is constituted by the non-minded activities of millions of single neurons (cf. Tomasello 2014: 33). Rather, what we have in hive cognition, as in a brain, is a division of labor between many parts of some greater individual, and it is that individual — the hive or the brain-that is the cognitive agent. In short, hive cognition is not collective but individual cognition.

What strikes me as right about this response is that it rests on the point that the integration of the individuals in social insect colonies makes very much for an entity that is at least organism-like, one of our paradigms of individuals with intentionality (Wilson and Barker 2017). But that is also true of the human social groups that have been central to the core work on collective intentionality, which is why they have been considered to be persons (e.g. Pettit 2003) or "true believers" (Tollefsen 2002), and the subjects of moral responsibility. If the individual-like character of human social groups is not only no barrier to entertaining the question of whether there might be collective intentionality at play, but one of the signs that we are considering human social groups of the right kind in taking up that issue, then the individual-like character of hives, nests, swarms, and colonies of social insects should be viewed in just the same way.

Theiner views being composed of components that are themselves intentional agents as a necessary condition for some entity to be a candidate for collective intentionality. Can we accept this condition and still view hive cognition as exemplifying the group mind hypothesis? I think so, since it is plausible to view individual members of the hive as having some; limited, form of intentionality, just not the rich level of intentionality that seems to emerge in the hive's actions. But should we accept Theiner's condition, or (for that matter) Schweikard and Schmid's characterization of collective intentionality as 'the power of [individual] minds to be jointly directed'? Once we recognize that the singular or individual-level intentionality can be significantly distinctive in both its "propositional" and "attitudinal" dimensions from that at the collective level, such views seem to me more plausible-more plausible, but also less apt for ruling out hive cognition as a form of collective intentionality.

In defending hive cognition as exemplifying a type of collective intentionality or group mind, Bryce Huebner (2013: 230-33) has noted that social insects should be thought of as exemplifying minimally collective mentality, and that it would be misleading to think of them as having mental states such as beliefs and desires. Despite lacking what I have previously called full-blown minds, they nonetheless possess or participate in some relatively constrained sets of focal processes or abilities, such as decision-making, planning, or monitoring (R.A. Wilson 2004: 290-91). Since it is this kind of minimal-mindedness that has been contested in discussions of group minds in human social groups, the fact that hive minds lack the full range of intentional states that individual cognizers possess is no reason to deny them group-mindedness. And if there can be group minds without individual intentionality of the appropriate kind-perhaps just more restricted forms of individual intentionality - then the idea that collective intentionality must derive, in some way, from individual intentionality, cannot be correct. 
Although so far I have been shifting between talk of group minds and collective intentionality, it is at this point that a defender of the standard view of collective intentionality, according to which collective intentionality derives from individual intentionality, might insist on a firm distinction here. The thought here is that whatever we say about group minds in social insects is completely independent of what one should say about genuinely collective intentionality in humans and their closest biological relatives. As Tomasello says,

Cooperation by itself does not create complex cognitive skills-witness the complex cooperation of the cognitively simple eusocial insects and the cooperative child care and food sharing of the not-so-cognitively-complex New World monkeys, marmosets and tamarins.

(Tomasello 2014: 33)

While Tomasello is certainly correct that the enriched "we-intentionality" whose ontogeny and phylogeny he explores is missing in eusocial insects and other non-human animals-individual intentionality here is, at best, very limited-it is less clear that one can simply bracket off the corresponding forms of collective action, whether they be merely distributive or joint shared. Indeed, if one can have both of these forms of collective action in psychologically more impoverished circumstances, as I want now to suggest, such we-intentionality cannot hold the key to understanding of acting collectively.

\section{SOCIAL PLAY AND TERRITORY MARKING: HIGHLY SOCIAL MAMMALS}

In past work (R.A. Wilson 2007) I have argued that social play and territory marking in non-human animals such as canids poses another kind of challenge to the picture of collective intentionality as requiring an enriched, individualistic form of intentionality. Although part of that argument was directed at particular claims-about sociality, institutional reality, and status functions-central to John Searle's (1995) answers to the questions "what is social reality?" and "what are social facts?", part of the argument suggests that there can be a kind of joint or shared intentionality amongst non-human animals that stops short of the full-blown sharing of we-intentions that now form a deep bedrock in our own sociality.

Social play of the kind that is readily observed in domestic dogs (and less-easily observed in non-domestic dogs) involves multiple individuals responding to one another's recognizably play-signaling behaviors, such as arched bows, mock bites, tail-nipping, and back-rolling. Social play in canids, like social play in human children, is not simply behavior, but behavior that is recognized by the participants in it as play, as something that both or all participants undertake. Like territory marking, social play functions via individual intentionality that is sensitive to the social context in which the activity takes place. Here shared intentionality gains purchase, I want to suggest, not so much through the generation of playful or territory-marking activity, but through its reception as playful or territory-marking. When other conspecifics stop treating a behavior as playful, play ends, just as their ignoring of a scent as marking out territory takes away that scent's territory-marking function. 
Both social play and territory marking in canids and, I think, other highly social mammals, are collective acts involving participants with at least some kind of second-order intentionality. I also think that such activities involve some level of joint or shared intentionality since they require that mere behaviors and scents be taken by participants as signals of the respective intentionality-laden activities of play and territory marking. In this respect, they are representative of a large class of non-human animal behavior, including grooming in primates and collective food-sharing in bats, that are generated and underwritten by individual-level intentionality that is other-directed in the way that we-intentionality is. Such multilevel traits-play, territory marking, grooming, and food sharing-could be explained as either an appeal to group-level intentionality or to individual-level intentionality. As such, the challenge posed by the social manifestation thesis to proponents of the group mind hypothesis remains live: do we need to posit intentionality at the group level, as I suspect we do need to in the case of social insects, in order to explain this collective behavior, or can we make do with an appeal to individuallevel, socially manifested intentionality?

To come back to the conception of collective intentionality exemplified by Searle and Tomasello, note that whatever intentionality there is in such cases, it is related to neither "institutional reality" nor the enriched forms of we-intentionality central to their conceptions of collective intentionality. This itself does not imply either that collective intentionality plays a special role in structuring institutional facts, or that there are no forms of shared intentionality that are distinctively human. But it does suggest that we need a view of the relationship between sociality and intentionality, both individual and collective, that departs from the individualistic tradition to which both Searle and Tomasello are committed.

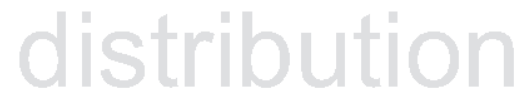

\section{CONCLUSION}

The relationships between sociality, collective intentionality, and individuals can inform how we think of each of these three relata. I have suggested that Schweikard and Schmid's individual ownership claim, that 'intentionality is had by the participating individuals, and all the intentionality an individual has is his or her own' can be satisfied in at least many cases by accepting the social manifestation thesis, particularly by non-individualistic versions of that thesis. Collective intentionality might well be possessed by individuals without itself being individualistic.

Collectively acting is widespread in the non-human animal world. Some of this collective action is merely distributive, but some of it is very likely also shared or joint, in the senses in which I have introduced those terms. This does not itself imply that collective intentionality has a corresponding range, but it does mean that the very same explanationist motivation for positing collective intentionality in human groups applies to non-human animals.

The significance of the social insects in the present context is that they represent a range of cases in which we have both merely distributed and shared or joint collective action without much individual intentionality at all. Thus, we either allow that such collective action can take place without collective intentionality at all, or that there is collective intentionality without we-intentions.

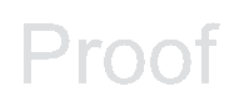


The significance of social play and territory marking in highly social mammals, such as canids, is that they represent cases in which we have shared or joint collective action with individual intentionality that stops short of the full-blown, institution-laden forms of we-intentionality that structure much of our own social life. Thus, we either allow, as with the case of social insects, that such collective action can take place without collective intentionality at all, or that there is collective intentionality of some type that exists independent of distinctively human psychology and institutional reality.

\section{RELATED TOPICS}

Collective Action and Agency (Ch. 1), Collective Memory (Ch. 11), Distributive Cognitive Systems (Ch. 18), Social Construction and Social Facts (Ch. 20), Development of Collective Intentionality (Ch. 31), Origins of Collective Intentionality (Ch. 33).

\section{REFERENCES}

Adams, F. and Aizawa, K. (2008) The Bounds of Cognition, Oxford: Blackwell.

Barnier, A., Sutton, J., Harris, C. and Wilson, R.A. (2008) "A Conceptual and Empirical Framework for the Social Distribution of Cognition: The Case of Memory," Cognitive Systems Research 9 (1-2): 33-51.

Boag, Z. (2014) "Searle: It Upsets Me When I Read the Nonsense Written by My Contemporaries," New Philosopher January 25, 2014. www.newphilosopher.com/articles/john-searle-it-upsets-me-when-iread-the-nonsense-written-by-my-contemporaries/ Retrieved July 24, 2014.

Brentano, F. (1874) Psychology from an Empirical Standpoint, translated by A.C. Rancurello, D.B. Terrell and L. McAlister, London: Routledge, 1973.

Chant, S.R., Hindriks, F. and Preyer, G. (eds) (2014) "Introduction: Beyond the Big Four and the Big Five," in From Individual to Collective Intentionality: New Essays, New York: Oxford University Press: 1-9.

Clark, A. (2008) Supersizing the Mind: Embodiment, Action, and Cognitive Extension, New York: Oxford University Press.

Clark, A. and Chalmers, D. (1998) "The Extended Mind," Analysis 58: 10-23.

Gilbert, M. (1996) Living Together: Rationality, Sociality, and Obligation, New York: Rowman and Littlefield.

Huebner, B. (2013) Macrocognition: A Theory of Distributed Minds and Collective Intentionality, New York: Oxford University Press.

MacIver, M. (2009) "Neuroethology: From Morphological Computation to Planning," in P. Robbins and M. Aydede (eds), Cambridge Handbook of Situated Cognition, New York: Cambridge University Press.

Pettit, P. (2003) “Groups with Minds of Their Own," in F. Schmitt (ed.) Socializing Metaphysics: The Nature of Social Reality. New York: Rowman and Littlefield.

Rupert, R. (2005) “Minding One’s Own Cognitive System: When is a Group of Minds a Single Cognitive Unit?” Episteme: A Journal of Social Epistemology 1(3): 177-188.

-__ (2009) Cognitive Systems and the Extended Mind, New York: Oxford University Press.

___ (2014) "Against Group Cognitive States," in S.R. Chant, F. Hindriks, and G. Preyer (eds) From Individual to Collective Intentionality: New Essays, New York: Oxford University Press.

Schweikard, D.P. and Schmid, H.B. (2013) "Collective Intentionality," in E.N. Zalta (ed.) The Stanford Encyclopedia of Philosophy (Summer 2013 edition), http://plato.stanford.edu/archives/sum2013/entries/ collective-intentionality/.

Searle, J. (1990) "Collective Intentions and Actions," in P. Cohen, J. Morgan, and M.E. Pollack (eds) Intentions in Communication, Cambridge: Bradford Books.

-_- (1995) The Construction of Social Reality, New York: Free Press.

-_- (2010) Making the Social World: The Structure of Human Civilization, New York: Oxford University Press.

Seeley, T. (1995) The Wisdom of the Hive, Cambridge, MA: Harvard University Press. 
- (1997) "Honey Bee Colonies are Group-Level Adaptive Units," The American Naturalist 150 (sup.): 22-41.

- - (2003) "Consensus Building During Nest-Site Selection in Honey Bee Swarms: The Expiration of Dissent," Behavioral Ecology and Sociobiology 53: 417-24.

Seeley, T. and Visscher, P. (2003) "Choosing a Home: How the Scouts in a Honey Bee Swarm Perceive the Completion of Their Group Decision Making," Behavioral Ecology and Sociobiology 54: 511-20.

Seeley, T., Camazine, S. and Sneyd, J. (1991) "Collective Decision-Making in Honey Bees: How Colonies Choose Among Nectar Sources,” Behavioral Ecology and Sociobiology 28: 277-90.

Sneddon, A. (2011) Like-Minded: Externalism and Moral Psychology, Cambridge, MA: MIT Press.

Theiner, G. (2014) “A Beginner's Guide to Group Minds," in J. Kallestrup and M. Sprevak (eds) New Waves in Philosophy of Mind, Boston, MA: Palgrave Macmillan.

Tollefsen, D. (2002) “Organizations as True Believers," Journal of Social Philosophy 33(3): 395-411.

Tomasello, M. (1999) The Cultural Origins of Human Cognition, Cambridge, MA: Harvard University Press.

Tomasello, M. (2014) A Natural History of Human Thinking, Cambridge, MA: Harvard University Press.

Tuomela, R. (2007) The Philosophy of Sociality: The Shared Point of View, New York: Oxford University Press.

Wheeler, W.M. (1911) "The Ant-Colony as an Organism," reprinted in his Essays in Philosophical Biology, Cambridge, MA: Harvard University Press, 1939.

Wheeler, W.M. (1920) “The Termitodoxa, or Biology and Society," reprinted in his Essays in Philosophical Biology, Cambridge MA: Harvard University Press, 1939.

Wheeler, W.M. (1923) Social Life Among the Insects, New York: Harcourt Brace.

Wheeler, W.M. (1926) "Emergent Evolution and the Development of Societies," modified version reprinted his Essays in Philosophical Biology, Cambridge, MA: Harvard University Press, 1939.

Wilson, D.S. (1997a) "Altruism and Organism: Disentangling the Themes of Multilevel Selection Theory," American Naturalist 150 (supp.): S122-S134.

- - - (1997b) "Incorporating Group Selection into the Adaptationist Program: A Case Study Involving Human Decision Making," in J. Simpson and D. Kendrick (eds) Evolutionary Social Psychology, Hillsdale, NJ: Erlbaum.

Wilson, R.A. (1994) “Wide Computationalism," Mind 103: 351-72.

- - (1999) "Philosophy: Introduction," in R.A. Wilson and F.C. Keil (eds) The MIT Encyclopedia of the Cognitive Sciences, Cambridge, MA: MIT Press.

- - (2001) "Group-Level Cognition," Philosophy of Science 68 (supp.): S262-S273.

_-_ (2004) Boundaries of the Mind: The Individual in the Fragile Sciences: Cognition, New York: Cambridge University Press.

_- (2007) "Social Reality and Institutional Facts: Sociality Within and Without Intentionality," in S.L. Tsohatzidis (ed.), Intentional Acts and Institutional Facts: Essays on John Searle's Social Ontology, Dordrecht: Springer.

- - (2014) “Ten Questions Concerning Extended Cognition," special issue of Philosophical Psychology, edited by T. Sturm and A. Estany, 27(1): 19-33.

Wilson, R.A. and Clark, A. (2009) "How to Situate Cognition: Letting Nature Take Its Course" in P. Robbins and M. Aydede (eds) Cambridge Handbook of Situated Cognition, New York: Cambridge University Press.

Wilson, R.A. and Barker, M.J. (2017) “The Biological Notion of Individual," in E.N. Zalta (ed.) The Stanford Encyclopedia of Philosophy (Spring 2017 edition), http://plato.stanford.edu/archives/spr2017/entries/ biology-individual/ 